\title{
Soft Computing Approach for Measuring Business Process Agility in an Agile Environment
}

\author{
Aarti M. Karande \\ Research Scholar Computer Engineering \\ S.P.I.T. Mumbai
}

\author{
D. R. Kalbande, $\mathrm{PhD}$ \\ Professor, Dean (Industry Relation), HOD \\ Computer Engineering, S.P.I.T. Mumbai
}

\begin{abstract}
Agile environment checks Organization's capacity or flexibility to accept the changes. Working in agile development needs to check their process, effect in the collaboration with other processes present in the enterprise solution. But agile environment is unpredictable. Hence to measure the process agileness, soft computing approach is used. In this paper, Hybrid Neuro-fuzzy approach is proposed to measure agility of business process with respect to the architectural level. This approach uses different weighting algorithm, for fully connected neural network evaluated on the basis of pairwise comparison of process type and architecture type. This method can be used to take check importance or effect of change of process used in the software solution used in the industry. In case of changing environment, this method will give a selection path to expert for selection of changes in the enterprise solution.
\end{abstract}

\section{Keywords}

Business Process Agility, Neural Network, Agile development

\section{INTRODUCTION}

An enterprise software solution may be made of a number of complex and interrelated applications. As per working style, applications can be classified into enterprise architectural levels. As per the changing environment, these applications are more prone to change as per stakeholder's requirement, process logic, or data. This paper shows soft computing techniques used for monitoring process agility using Neurofuzzy hybrid approach. Section I explains an architecture framework with different type of business processes. Section II shows proposed hybrid approach for measuring agility. This section focus on neural network structure used to find process criticality and fuzzy logic used to handle uncertainty of input data to find agility of the process. Section III shows real time case study working on agile methodology is analyzed with hybrid approach for monitoring business process agility.

\section{ENTERPRISE SOLUTION WITH AGILE DEVELOPMENT}

Enterprise solution is the software used in the organization as per the business requirement of the product. Following section gives details about the enterprise solution.

\subsection{Agility in enterprise solution}

[61] Enterprise solution is made of a sequence of simple or complex business process working as per business policy. Each business process may face challenges of changes based on techniques like flexibility or agility. Flexibility is defined as the general capacity to react to changes depending on the market changes, whereas agility can be defined as the speed in responding to changes depending on the market requirement. The flexibility and agility both depends on the ability of cooperating organizations to adapt. [12] Agility, but not the flexibility, is the important key to business process's ability to survive and succeed in the changing environment of the organization. [31] Currently used enterprise solutions are more process-centered, hence agile solution can be more optimized by furnishing resources and services. [6] Agility can be differentiated as operational agility, organizational agility, deployment agility, sustainability agility, acquisition agility, and conceptual agility. To measure agility, different techniques are used. These different techniques are As-Is strategy, Re-engineering of the process flow, structural complexity of the system, calculating ability of changes as per system requirement of enterprise solution.

\subsection{Enterprise Architecture}

Enterprise solution used in the organization can be classified into different architectural level. Architectural level also classifies its working processes based on its working. This process executes as per the business policy. [13] Enterprise architecture is a well-organized structure for analyzing, designing, and implementing software solution. Business architecture works as per the organization's mission and vision. Information architecture builds its knowledge pattern based on the working of applications. Data architecture builds and stores data as per application. Technology architecture gives a platform for storing and working in different hardware and software required for all above architectures. [3] [60] Business processes can be differentiated as Management, Core, Enabling and Enhancing process depending on its execution type. [50] [59] Management process represents business logic of an organization. Core process is mostly designed using management process logic for core working of the enterprise solution. Enhancing process is designed based on the core processes for improving quality of execution. Enabling process is designed for enhancing work of the core processes. Enabling and enhancing processes can be executed in parallel or in sequence for core processes or for management processes. [46] Management processes can be designed for information, data, application or technology levels. [19] [49] Core process can be designed at all levels for developing organizational logic. Enabling and enhancing processes can run in accordance with the core and management processes.

\subsection{Agile Environment}

[61] Organization faces agile behaviors due to the growing demand in the market for resources, services, or products. [7] [36] Agility drivers are the parameter which is responsible for changes in the business environment. It also motivates the changes in the organizational strategy. Agile capabilities are the parameters which provide the ability for detecting patterns and adapting business processes as per the required events. Agile enablers are the parameters which creates a situation as per the changes so that changes can affect the working of the process. [7] Agile Manufacturing rules can be defined as statements, which can change very quickly. The agile product 
life cycle is very short and response time is also short. Agile products are high level quality and wide-ranging services. Being constant or to update with changing parameters are the important objective of this research area. Hence this paper gives an opportunity to measure or to monitor the agile parameter of the business process present in the enterprise solution.

\section{SOFT COMPUTING TECHNIQUES}

[9] [28] In comparison to conventional AI techniques or hard computing, soft computing deals with precision, certainty and rigorous environment. [55] Soft computing is to achieve problems such as the tolerance for imprecision, uncertainty, robustness, and partial truth. [55] [11] [22] Soft computing is more oriented towards the analysis and design of intelligent systems working as per the uncertainty and imprecise environment. Soft computing can be used in many application areas such as process control, engineering design, financial trading, credit evaluation, medical diagnosis, and a cognitive simulation.

\subsection{Neural Network}

[32] [5] Neural network works as per the observations in the information systems. It generalizes the output by abstraction, Connection strengths between neurons, and memory used to store the knowledge. Training a neural network includes modifying the weights, adapting its connections to get the desired behavior for all input patterns. [17] Neural network can be used to learn new associations, new functional dependencies and new patterns from the same input data. In case of complex structure, input and output are dependent on each other depending on its connection type. [39] [4] Number of iterations for training algorithm and the convergence time for finding output will depend on the weight initialization within the neurons. [41] In a fully connected neural network structure all neurons are connected to each and every neuron. This structure is having high strength for fault tolerance. Applications of neural networks are pattern recognition, classification, data-mining, prediction systems, Sales forecasting, Industrial process control, Customer research, Data validation.

\section{[44] [42] Advantages of neural networks are}

- Its adaptivity to optimize their output behavior as a pattern recognizer, decision maker, system controller, predictor, etc. by automatically adjusting their weights.

- Neural networks are highly accurate for float values.

- Construction of neural network is very easy. Only need to remember connection nodes.

- Neural networks learn the relationship between independent variables and dependent variables.

- Neural networks work as a black box for classification or for pattern generation.

- It helps to minimize a quadratic error function.

Disadvantages of using neural networks are its lack of transparency due to assignment of weights. Its output knowledge or the pattern is difficult to understand due to threshold value or training pattern.

\subsection{Fuzzy logic}

[33] [7] [16] [1] Fuzzy logic is applied to decision making in uncertain and ambiguous situations. It decreases ambiguities and increases the effectiveness of decisions. [44] [10] In fuzzy logic, every input is working as a matter of degree range defined in the range of $[0,1]$. [39] Fuzzy Logic represents undetermined, unknown, or intermediate truth-values. [35] [38] A fuzzy set can be represented by number of membership functions such as Triangular, Trapezoidal, Gaussian, and Polynomial. [8] $\alpha$ cut for membership function defines a selection of membership functions. Membership function needs to map for scale invariance, shift invariance, sign invariance and union invariance for specified range. A membership function is used to quantify a linguistic term from crisp term. A membership function determines each point in the given input space mapped using degree of membership value. [64] Overlapping of membership function improves classification and interpretability of calculated results. [36] [24] Defuzzifier combines the output sets corresponding to all fired rules in significant way to obtain only a single output set.

[14] Triangular fuzzy numbers are fuzzy numbers with a base value for lower, core, and upper values. Discourses of the specified variables which have a positive degree may fire atleast one rule as per specified range. A greater resolution is achieved with a high range of membership functions. The triangular approximation is reasonable for fuzzifying the input crisp value and provides fuzzy solutions with much smaller spread. [2] Selection of a triangular member function gives the simple way for fuzzification. Triangular method is a simple and easy for learning of the antecedent and consequent parts of the fuzzy IF-THEN rules. When number of rules decreases, it represents a lower computational complexity.

Advantages of Fuzzy logic are [42]

- It does not require specifying concrete values of properties depending on the current understanding of the problem.

- Fuzzy logic is viewed as a limiting case of approximate reasoning which is characterized by its exact reasoning.

- Fuzzy classifiers generate a list of if-then rules represented in linguistic forms which can be easily interpretable by users.

- If development capability, generalization, number of factors increases, calculating the uncertainty will be quite responsive and easy. [53]

Disadvantages of Fuzzy logic are defining as many rules as possible, and as per the degrees of acceptance. [15] Defuzzification works according to singleton output membership function.

[63] The fuzzy logic controller system is capable of approximating a compact set to arbitrary accuracy. It works as universal approximators. [21] There are two main types of controller system, defined as Mamdani fuzzy systems and Takagi-Sugeno fuzzy systems. A Sugeno fuzzy system is computationally efficient and works well with linear techniques. It works well with optimization and adaptive techniques. It is well suited to mathematical analysis. Mamdani fuzzy system is intuitive and has widespread acceptance. It is well suited to human input. [40] [62] To apply the fuzzy logic concept to a real time application, the following steps are used

- In fuzzification crisp data is converted into fuzzified data using selected Membership Functions.

- In Fuzzy Inference Process, membership functions combine fuzzified data using control rules to derive the fuzzified output.

- In defuzzification, defuzzification methods are used to calculate each associated output and put them into the memory. 


\subsection{Hybrid approach}

[54] [65] [55] Intelligence techniques based on hybrid soft computing approach can develop decisions of the enterprise solution. Fuzzy logic gives the quality control. Neural networks as the capabilities of a supervised learning algorithm, performs the fine-granule local optimization. [56] Neural Networks has the capability of self-learning, while the fuzzy logic inference system is capable of dealing with fuzzy information and simulating decision making as that of the human brain. [4] Fuzzy logic rule sets can always be translated into easily understandable linguistic rules, but rules cannot be learnt in the same way as that of neural networks. Neuro-fuzzy approach can overcome their individual drawbacks if they are combined together. Neural network with their learning capabilities can be used to learn fuzzy decision rules. [11] A fusion of neural networks and fuzzy systems provides learning as well as readability of the changeable adaptive topologies of the fuzzy systems.

[26] [48] [47] Based on the training data, neural network and fuzzy logic system determines their properties as that of human's process information. During the training procedure, rule parameters for antecedent and consequent will be tuned to minimize computing error. [43] Neuro-fuzzy systems combine linguistic and numerical information. Fuzzy if-then rules with specified range are based on linguistic information supported by neural network.

\section{PROPOSED SYSTEM TO FIND AGILITY OF THE PROCESS}

Combining the features of hybrid system based on Neuro fuzzy approach, this paper proposes a system to measure agility of the enterprise solution as shown in figure 1 . In phase 1, neural network will find process criticality and in phase 2, fuzzy logic rule base will find the agility of the process. This incorporates the optimization of the problem using a hybrid solution approach. Input for neural network phase is process importance, parameter importance taken from the user and generates process criticality. In phase 2, fuzzy system generates business process agility as output based on the input provided for neural network. Rule base is constructed based on the criticality of the process and criticality of the parameter. This helps to find agility of the process with respect to the affected parameter.

\subsection{Phase 1 - Neural Network system}

The neural network system structure is of fully connected type. All the neurons present in the layers are connected to each other. Each connection is having weights assigned to each neuron. Input to the neural network is the process importance for finding process criticality and parameter importance for finding parameter criticality. Process importance and parameter importance is a value between $\{1 \ldots 10\}$ showing its importance from lower to higher scale. [57] Using saaty's method for pairwise comparison of architectural level and process type, weights are calculated for different architectural levels. Pairwise comparison is different for each organization; hence weight for each neuron will be different. Output is generated considering the importance of all nodes. Due to simplicity of the triangular function value for its component are taken from the user only.

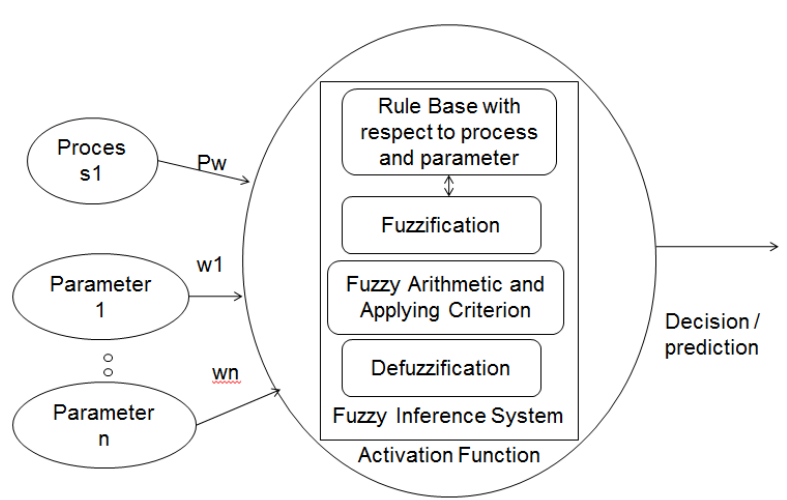

Fig. 1: Proposed hybrid soft computing Approach

In the proposed system, two neural networks structures are considered. One for finding process criticality and another for finding parameter criticality. Depending on the type of neural network system, it will have hidden layers defined for architectural level, process type and parameter type. [49] As shown in the figure 2 , process criticality is calculated by fully connected neural network based on hidden layers for architecture type and process type. The formula used for finding process criticality is as shown in equation 1 . In the same way, parameter criticality is calculated using formula as shown in equation 2. Parameter criticality is calculated by fully connected neural network based on hidden layers for architecture type, process type and parameter type. Based on the organizational business policy, process importance and parameter importance value ranging from 1 to 10 is taken from user.

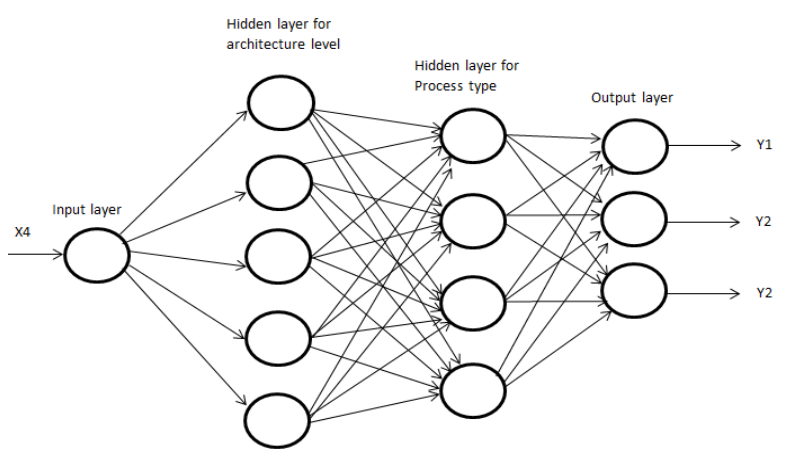

Fig. 2: Fully connected Neural Network for Parameter Type

Criticality of Process $=$ Process importance $*$ Weight of Process at specified architectural level * weight of process at specified process type ----------- (1)

Criticality of Parameter $=$ Parameter importance $*$ Weight of Process at specified architectural level * weight of process at specified process type * weight of parameter type

For fully connected neural network, connectivity weights are calculated based on different algorithms. This algorithm calculates the eigen vector, for input pairwise comparison matrix as per saaty's method of calculation. Following are the suggested weighting algorithm

1. Geometric Average Approximation (GA): GA is an arithmetic mean calculation method. It gives an average mean of the input matrix. This method works on the rate of return concept that connects the starting and ending values of range, if it is considered in all periods of calculation. It works on relative measure of the data. 
2. Exact Linear Algebra Calculation (EA): EA computes an exact solution of a problem calculating a solution of linear equations with input as precise value, integers modulo, a prime number, or residues modulo a minimum polynomial. [18]

3. Successive Matrix Squaring (SMS): [34] SMS works on the policy for displacement rank with given specified ranges. [29] Parallel matrix generated at the end of each calculation, changes the elements of the original matrix. [51] SMS shows a deterministic iterative algorithm based on a repetitive matrix squaring scheme.

4. Analytical Hierarchical Processing (AHP): [20] [57] AHP considers the problem divided into a hierarchy of sub problems which is subjectively evaluated. This makes the problem easy to solve and for calculation as per sub problems. Normalized eigenvector of this matrix are the relative weight of input vector.

\subsection{Phase 2- fuzzy logic System}

[25] Fuzzy logic works in uncertain environment, working as per the linguistic nature. In phase 2, triangular membership function is used for Fuzzification. Crisp value is converted into fuzzified value using the triangular membership function. [41] In proposed method, fuzzy logic develops a rule base comparing process type with parameter type. This rule base shows relation between the process and parameter as per organization policy. [10]

[45] [10] [58] Rule base is constructed with the help of business expert's view for the architectural level to the process type and for the process type to the parameter type. Rule base maps process criticality with [30] [23] Table 1 shows an example of the rule base created for fuzzified value of process and parameter criticality. This table may have different values for different organization based on organizational business policy.

\begin{tabular}{|l|l|l|l|}
\hline $\begin{array}{l}\text { Parameter } \\
\text { Process }\end{array}$ & $\begin{array}{l}\text { Low } \\
\text { critical }\end{array}$ & $\begin{array}{l}\text { Avg. } \\
\text { critical }\end{array}$ & $\begin{array}{l}\text { High } \\
\text { Criticality }\end{array}$ \\
\hline Low critical & Not Agile & Less Agile & Avg. Agile \\
\hline Avg. critical & Less Agile & Avg. Agile & More Agile \\
\hline High Critical & Avg. Agile & More Agile & High Agile \\
\hline
\end{tabular}

Table 1: Rule base for Fuzzy logic

Process agility is the defuzzified output value using the centroid method. In Centroid defuzzification method, the area of each resulting set is multiplied by the domain values passing through its center. Phase 2 gives an output showing agility of the process with respect to the parameter. The output of each processor can be aggregated using the centroid defuzzifier to obtain a crisp value as agility. [52] The agility value of a parameter with respect to the process shows its agility within the process. This value shows the percentage that parameter may change or may be volatile with respect to the process. Calculated agility value shows the relationship of agile parameter with respective architectural level and as per process type. This agility value of the process may help in taking decisions related to agility constraints. It helps for finding the impact of change with respect to the process for respective architecture level. [27]

\section{CASE STUDY FOR BUSINESS PROCESS AGILITY 5.1 ABC Company for Health Fidelity System}

ABC Company works in an agile development mode. It works in agile mode for accepting the changes in technology or in process execution. ABC Company works for Health Fidelity system (HF) where input health data is changing as per organizational environment. Client requirement makes system agile for execution of certain process. HF System works on Natural Language Processing technology and suggest platform to analyze vast amounts of unstructured data in order to provide clinical and financial insights. This system works for finding risk analytics of people based on their health history.

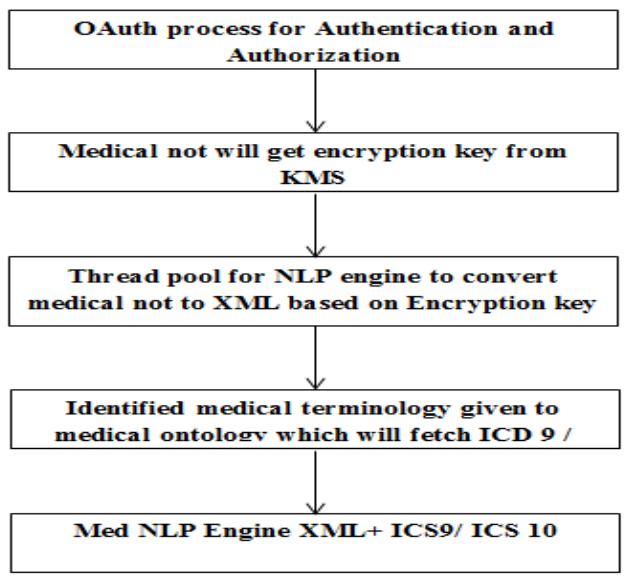

Fig. 3: Working of MedNLP Engine

This system predicates an insurance to be issued to a user based on the predictions made. MedNLP Engine - HF System is a core module for converting medical history into XML format. This conversion is done by NLP engine. This application helps for the payer and provider of organizations to address risk and quality in the value-based payment models. This application is designed using real-world workflow for input from authenticated health plan, a key development partner and strategic investor. HF is used for transforming risk adjustment. This application offer a combination of technology and expertise that enable Medicaid health plans to transform manual risk adjustment process into an integrated workflow. With HF, user will gain better visibility, control and predictability into user plan's risk adjustment activities for user's operational, compliance, and financial performance. HF process flow is as showing in figure 3.

\subsection{Agile Environment for HF system}

HF system's working analysis is done as shown in table 2 . This table shows each process working as per management, core, enabling and enhancing with respect to each architectural level. This relation shows processes working at different architecture level along with agile parameter. From this table, it is observed that for HF system, most of the processes from application level are agile. Application level works on PAAS and web services technology. Web services work on reusability and responsiveness. Applications with agile parameter also effect on the speed of execution. Client changes health data or working style of the process which may affect agility. Hence, most agile architecture is 
application architecture as compared to the other architecture level.

Agility drivers are the parameter from users or administrator affecting the health plan requirement. This data may be changing as per user. The administrator will also change health plan as per the business policy. For user, data attributes are working style of user, gender, Location etc. For administer, attributes are terms of the health plan, waiver in the health plan. This attribute may changes as per the change in the business policy.

Agile capabilities are the parameters which get affected and hence propagate to impact further changes. In case of user's data, it may provide the ability for detecting patterns and adapting business processes as per the events. Plan may include an exception for certain user data. They incorporate the changes, but with the substitution. E.g. user now affected with diseases and still he can continue with existing plan. Administer may make certain changes in the execution of the plan. Group plan for health may include floating value options as per changes.

Agile enablers are the parameters which capture and bring it in visibility to support efficient development and delivery of future changes. This parameter affects agile manufacturing rules. E.g. Infrastructure or environment can be the agile enablers for the user's health. [7] Agile Manufacturing rules can be defined as statements, which can change very quickly. The agile product life cycle is very short and the time delay in response is also short. It can be unpredictable. Agile products are with very high levels of quality and wide-ranging services.

\subsection{Process Management Tool Based on \\ Neuro - Fuzzy approach}

Process Management tool is based on Neuro-fuzzy based hybrid approach. This tool helps to measure agility value of business process. This tool is made using JAVA programming language with back end as MySql. The following pages are made in the process management tool.

- Add process page: This page will take process information like working architectural level, type of process and process importance of application. Here the user will select weighting algorithm to calculate process criticality.

- Add parameter page: Here a user needs to give information as type of parameter and parameter importance for the selected process type.

- $\quad$ Assign membership values for process / parameter: This page is used for assigning linguistic values using the triangular membership function to process and parameter. For triangular function values for low, average or high is taken from the user based on the intuition method of Fuzzification given by the expert of the system.

- $\quad$ Assign Rule base page: Rule base pairwise relation for process criticality and parameter criticality may be different as per Company's requirement for all types of combination of process type with parameter type along with different architectural level.

- Assign weight for process and parameter: This page is used for adding pairwise comparison for architectural level, process type, and parameter type.

- View agility: This page gives results as the agility of the process based on the parameters. This page shows, agility constraint, framework relation selected for that process.

\subsection{Case study for process Plogin}

Process management tool is used for measuring business process agility for single process named Login. In order to check more agile architectural level or more agile process type only one process information is applied to all architectural levels and all process types for all combinations of the parameter type. Architectural level with one business process helps to find behavior of all architecture w.r.t to one perspective.

Abbreviation used: Management Process: MP, Core process: $\mathrm{CP}$, Enabling process: EP and Enhancing process: EEP

Architectural Level: ArL, Process type: PT, weighting type: WT, Agility Value: AV

\begin{tabular}{|c|c|c|c|c|c|c|c|}
\hline \multicolumn{8}{|c|}{$\begin{array}{l}\text { Process Information }: \text { Process name }=\text { Login, Process importance }=10 \\
\text { Input Parameter name }=\text { puname, Input parameter importance }=10 \\
\text { Output parameter name }=\text { ploginss, Output parameter importance }=10\end{array}$} \\
\hline ArL & $\begin{array}{l}\text { PT } \\
\end{array}$ & WT & $\mathrm{AV}$ & ArL & PT & WT & $\mathrm{AV}$ \\
\hline \multirow{16}{*}{$\mathrm{BL}$} & MP & GA & 0.021 & $\mathrm{AL}$ & MP & GA & \begin{tabular}{|l|}
0.739 \\
\end{tabular} \\
\hline & & ELA & 0.029 & & & ELA & 0.647 \\
\hline & & SSM & 0.023 & & & SSM & 0.730 \\
\hline & & AHP & 0.013 & & & AHP & 0.627 \\
\hline & $\mathrm{CP}$ & GA & 0.351 & & $\mathrm{CP}$ & GA & 0.190 \\
\hline & & $\overline{\text { ELA }}$ & 0.289 & & & ELA & 0.200 \\
\hline & & SSM & 0.326 & & & SSM & 0.192 \\
\hline & & AHP & 0.249 & & & AHP & 0.180 \\
\hline & EP & GA & 0.082 & & EP & GA & 0.082 \\
\hline & & $\overline{\text { ELA }}$ & 0.088 & & & $\overline{\text { ELA }}$ & 0.120 \\
\hline & & SSM & 0.098 & & & SSM & 0.088 \\
\hline & & AHP & 0.078 & & & AHP & 0.080 \\
\hline & EEP & GA & 0.044 & & EEP & GA & 0.034 \\
\hline & & ELA & 0.079 & & & ELA & 0.039 \\
\hline & & SSM & 0.044 & & & SSM & 0.035 \\
\hline & & AHP & 0.039 & & & $\overline{\mathrm{AHP}}$ & 0.029 \\
\hline \multirow[t]{16}{*}{ IL } & MP & GA & 0.182 & $\mathrm{DL}$ & MP & GA & 0.003 \\
\hline & & ELA & 0.183 & & & ELA & 0.004 \\
\hline & & SSM & 0.186 & & & SSM & 0.003 \\
\hline & & AHP & 0.173 & & & AHP & 0.002 \\
\hline & $\mathrm{CP}$ & GA & 0.067 & & $\mathrm{CP}$ & GA & 0.046 \\
\hline & & ELA & 0.073 & & & ELA & 0.046 \\
\hline & & SSM & 0.067 & & & SSM & 0.047 \\
\hline & & AHP & 0.063 & & & AHP & 0.036 \\
\hline & EP & GA & 0.026 & & EP & GA & 0.022 \\
\hline & & ELA & 0.033 & & & ELA & 0.023 \\
\hline & & SSM & 0.027 & & & SSM & 0.022 \\
\hline & & AHP & 0.023 & & & AHP & 0.020 \\
\hline & EEP & GA & 0.010 & & EEP & GA & 0.007 \\
\hline & & ELA & 0.012 & & & ELA & 0.009 \\
\hline & & SSM & 0.011 & & & SSM & 0.007 \\
\hline & & AHP & 0.009 & & & AHP & 0.006 \\
\hline \multirow[t]{8}{*}{$\mathrm{TL}$} & MP & GA & 0.011 & $\mathrm{TL}$ & EP & GA & 0.041 \\
\hline & & ELA & 0.012 & & & ELA & 0.044 \\
\hline & & SSM & 0.010 & & & SSM & 0.042 \\
\hline & & AHP & 0.009 & & & AHP & 0.034 \\
\hline & $\mathrm{CP}$ & GA & 0.091 & & EEP & GA & 0.015 \\
\hline & & ELA & 0.089 & & & ELA & 0.020 \\
\hline & & SSM & 0.088 & & & SSM & 0.015 \\
\hline & & AHP & 0.084 & & & AHP & 0.014 \\
\hline
\end{tabular}

Table 3: Database for process agility as per Architectural Level, Process Type and Weighting Algorithm 


\subsection{Observation for process Plogin}

Applying same process information to all architectural levels with possible combination of process type and parameter type; it is observed that the value of agility for application architecture is low compared to the other architectural level. Low value indicates the application level is more prone to changes.

- Process value is getting affected because of comparison values given by experts for pairwise comparison of architectural level with process type. ABC Company works on agile methodology; hence processes used here are quite changing compared to fixed processes

- In phase 1 , four different weighting algorithms are evaluated for calculating weight matrix. These weight matrices are compared for their performance for same process key point indicator as time, complexity, accuracy and the use of memory. Out of 4 different weighting algorithms, it is found that the Analytical hierarchical processing algorithm is having more preference for complexity and accuracy. It gives less output value for changes. AHP check the pairwise comparison for its relative index. Output of the phase 1, is criticality of the process and parameter using different mathematical model.

- Rule base for process criticality and parameter criticality gives better understanding in relation to the process importance with respect to the parameter importance.

- Using centroid method as defuzzification method, crisp values for agility are calculated. The centroid method finds the center of the calculated sum of agility value using the center of sum formula.

- Same process value when applied to all architectural level different values are outputted. It is observed that agility value depends on process importance given by the user.

- This company works in an agile environment, hence expert given values are more affective for application architecture. Less value as output, gives an architectural level as a most agile level. This shows that application architecture is highly agile compared to other level's agility.

\section{CONCLUSION}

Due to the agile behavior of the market, enterprises have increased in their complexity of working. Finding the effect of change of process agility in enterprise solutions, may help to find the effect of process in decision making. Neural network approach increases speed of execution and Fuzzy logic approach gives an approximately correct answer due to use of linguistic variable in the human thinking manner. Using hybrid approach, it is possible to take advantage of both the approach in one intelligent system. Checking agility for one process at all levels, it shows the application level is more sensible compared to other levels. Soft computing approach helps to handle human thinking, behavior to measure business process agility. A different organization will have different results based on their own mapping for different process type to different architectural level. As a result this concept will work as a generalized concept for all types of organization handling complex and agile enterprise solution. This concept can be enhanced to check the impact of architectural agility to more different type of applications. This research can be validated with different type of processes working in different domain to suggest agile architecture level. In the same manner, Neuro-Fuzzy approach can be replaced with other soft computing approach.

\section{REFERENCES}

[1] Asif Ali, Muhammad Yousif Elfadul (October 2009) Fuzzy Decision Making in Business Intelligence Application of fuzzy models in retrieval of optimal decision School of Engineering Blekinge Institute of Technology

[2] Aditi Barua, Lalitha Snigdha Mudunuri, and Olga Kosheleva (2014) Why Trapezoidal and Triangular Membership Functions Work So Well: Towards a Theoretical Explanation Journal of Uncertain Systems Vol.8

[3] Aarti M. Karande \& Dr. D.R. Kalbande (2015) "Business Process Analyzed factors affecting Business Model Innovation" International Conference on Nascent Technologies in the Engineering Field (ICNTE-2015)

[4] Angela Bower (July 2003) Soft Computing Tes Sell A Support Services PLC Issue V1.R1.M0

[5] A. Maithili Dr. R. Vasantha Kumari Mr. S. Rajamanickam (2012) Neural Network Towards Business Forecasting IOSR Journal of Engineering Apr, Vol. 2(4) 831-836 ISSN: 2250-3021

[6] Anthony H. Dekker Agility in Networked Military Systems: A Simulation Experiment 11TH ICCRTS Coalition Command And Control In The Networked Era Topics: C2 Analysis, C2 Modeling and Simulation, Network-Centric Metrics

[7] Behzad Shahrabi, (2011) The Agility Assessment Using Fuzzy Logic World Applied Sciences Journal 13 (5): 1112-1119, 2011 ISSN 1818-4952 @ IDOSI Publications

[8] Bernadette Bouchon-Meunier, Mariagrazia Dotoli, Bruno Maione (June 2016) On The Choice Of Membership Functions In A Mamdani-Type Fuzzy Controller Volume 6, Issue 6ISSN: 2277 128X International Journal of Advanced Research in Computer Science and Software Engineering

[9] Chapter I Ajith Abraham Hybrid Soft and Hard Computing Based Forex Monitoring Systems

[10] Ching-Torng Lin \& Chen-Tung Chen (MAY 2004) New Product Go/No-Go Evaluation at the Front End: A Fuzzy Linguistic Approach IEEE Transactions On Engineering Management, Vol. 51, NO. 2, 197

[11] Dragan Z. Šaletic (2006) On Further Development of Soft Computing, Some Trends in Computational Intelligence SISY 4th Serbian-Hungarian Joint Symposium on Intelligent

[12] D R Kalbande, G T Thampi, N T Deotale (2011) EProcurement for Increasing Business Process Agility International Conference and Workshop on Emerging Trends in Technology (ICWET 2011)-TCET, Mumbai, India

[13] David Chen \& Guy Doumeingts \& Francois Vernadat (September 2008) Architectures for enterprise integration and interoperability Computers in Industry 59(7):647659

[14] Evangelos Triantaphyllou and Chi-Tun Lin (1996) Development and Evaluation of Five Fuzzy Multiattribute Decision -Making Methods International Journal of Approximate Reasoning 1996; 14:281-310 Elsevier Science 
[15] Ebru Ardil and Parvinder S. Sandhu (2010) A soft computing approach for modeling of severity of faults in software systems International Journal of Physical Sciences Vol. 5, pp. 074-085, Feb 2010 ISSN 1992$1950 \odot$ Academic Journals

[16] Ehsan Kamalloo and Mohammad Saniee Abadeh (2014) Credit Risk Prediction Using Fuzzy Immune Learning Hindawi Publishing Corporation Advances in Fuzzy Systems, Article ID 651324, 11 pages http://dx.doi.org/10.1155/2014/651324

[17] Ezhilarasi G and Dhavachelvan P (October, 2010) Effective Web Service Discovery Model Using Neural Network Approach International Journal of Computer Theory and Engineering, Vol. 2,

[18] Erich L. Kaltofen, Arne Storjohann The Complexity of Computational Problems in Exact Linear Algebra Encyclopedia of Applied and Computational Mathematics, Bjorn Enquist, Mathematics of Computer Science, Discrete Mathematics, Johan Hastad, field, Springer.

[19] Fu-Ren Lin \& Yu-Huapai (May 2000) Using MultiAgent Simulation And Learning To Design New Business Processes IEEE Transactions On Systems, Man And Cybernetics Part A Systems And Humans, Vol. 30, No. 3

[20] Geoff Coyle (2004) Practical Strategy. Open Access Material. AHP () Pearson Education Limited

[21] Hao Ying (Nov 1998) General SISO Takagi-Sugeno Fuzzy Systems with Linear Rule Consequent Are Universal Approximators IEEE Transactions On Fuzzy Systems, Vol. 6

[22] Imre J. Rudas, János Fodor (2008) Intelligent Systems Int. J. of Computers, Communications \& Control, ISSN 1841-9836, E-ISSN 1841-9844 Vol. III, Spl. issue: Proceedings of ICCCC 2008

[23] Ian Cloete, (February 2006), Jacobus van Zyl Fuzzy Rule Induction in a Set Covering Framework IEEE Transactions On Fuzzy Systems, Vol. 14, No. 1, 93

[24] Jerry M. Mendel and Robert I. Bob John (May 2002) Type-2 Fuzzy Sets Made Simple in IEEE Transactions on Fuzzy Systems

[25] Joseph Bih (2006) Paradigm shift an introduction to fuzzy logic IEEE Potentials

[26] J. Jassbi, S.M. Seyedhosseini \& N. Pilevari (March 2010) An Adaptive Neuro Fuzzy Inference System for Supply chain Agility Evaluation International Journal of Industrial Engineering \& Production Research, Vol.20, No.4

[27] Kailan Shang, \& Zakir Hossen,(November 2013) Applying Fuzzy Logic to Risk Assessment and DecisionMaking Sponsored by CAS/CIA/SOA Joint Risk Management Section

[28] Kurhe A.B., Satonkar S.S., Khanale P.B. and Shinde Ashok (2011) Soft Computing and its Applications BIOINFO Soft Computing Volume 1, Issue 1, pp-05-07

[29] Lujuan Chen, E.V. Krishnamurthy, Iain Macleod (1994) Generalised matrix inversion and rank computation by successive matrix powering parallel Computing 20-297311
[30] Lala Septem Riza, Christoph Bergmeir, Francisco Herrera, and Jose Manuel Benitez (May 2015) Fuzzy Rule-Based Systems for Classification and Regression in R Journal of Statistical Software, Volume 65, Issue 6. http://www.jstatsoft.org/frbs:

[31] Malú Castellanos (2008) Challenges in Business Process Optimization Mexican International Conference on Computer Science

[32] M.L. Caliusco and G. Stegmayer Semantic Web Technologies and A'rtificial Neural Networks for Intelligent Web Knowledge Source Discovery Y. Badr et al. (eds.) Emergent Web Intelligence: Advanced Semantic Technologies, Advanced Information and Knowledge Processing, DOI 10.1007/978-1-84996-07792

[33] Meysam Shaverdi, Mahsa Akbari, Sajad Emamipour (2012) Using Fuzzy Multi Criteria Decision Making Approach For Ranking The Web Browsers International Journal of Economics and Management Sciences Vol. 1, No. 8,pp. $72-86$

[34] Marco Miladinovic, Sladjana, predrag (2011) Modified SMS method for computing outer inverses of Toeplitz matrices applied Mathematics and computation.

[35] Muhammad Siddique (2009) Fuzzy Decision Making Using Max-Min Method and Minimization Of Regret Method(MMR) Thesis for the degree Master of Science

[36] Nour mohammad Yaghoubi, Mahboobeh Rahat Dahmardeh (2010) Analytical approach to effective factors on organizational agility J. Basic. Appl. Sci. Res., $1(1) 76-87$

[37] Nilesh N. Karnik, Jerry M. Mendel (December 1999) Type-2 Fuzzy Logic Systems IEEE Transactions On Fuzzy Systems, Vol. 7, No. 6,

[38] Omar Adil M. Ali, Aous Y. Ali, Balasem Salem Sumait (March 2015) Comparison between the Effects of Different Types of Membership Functions on Fuzzy Logic Controller Performance International Journal of Emerging Engineering Research and Technology, ISSN 2349-4395

[39] Piero P. Bonissone, Yu-To Chen, Kai Goebel, and Pratap S. Khedkar (1999) Hybrid Soft Computing Systems: Industrial and Commercial Applications Proceedings of the IEEE, Special Issue on Computational Intelligence, Vol. 87, No. 9, pp. 1641-1667,

[40] Peter Buba Zirra, Timothy Umar Maigari and Wallace Ebinum Ossai Zirra et al, (June- 2016) A Fuzzy Based System for Determining the Severity Level of Osteomyelitis International Journal of Advanced Research in Computer Science and Software Engineering

[41] Qing Zhou, Yuxiang Wu, Christine W. Chan, \& Paitoon Tontiwachwuthikul (2011) "GHGT-10 From neural network to neuro-fuzzy modeling: applications to the carbon dioxide capture process" Energy Procedia 42066-2073

[42] Rajni Mohana, Deepak Dahiya (September 2012) An Optimized Business Service Directory for the ESB Platform in SOA International Journal of Computer Networks \& Communications (IJCNC) Vol.4, No.5, DOI : 10.5121/ijcnc.2012.4511 165 
[43] Rohit Srivastava, Jwalant Baria (July Aug 2012 ) Realization of Autonomous Soft Computing System Using Computational Intelligence Methods international Journal of Emerging Trends \& Technology in Computer Science (IJETTCS) Vol. 1, Issue 2, ISSN 2278-6856

[44] Robert Fuller Eotvos Lor (2001) Neuro-Fuzzy Methods for Modelling \& Fault Diagnosis Lisbon Budapest VACATION SCHOOL, August 31 and September 1

[45] Salwa Ammar, David Moore \& Ronald Wright (2008) Analyzing customer satisfaction surveys using a fuzzy rule-based decision support system: Enhancing customer relationship management Journal of Database Marketing $\&$ Customer Strategy Management (2008) 15, 91 - 105. doi: 10.1057/dbm.2008.2;

[46] Shan L. Pan, Gary Pan, Adela J. W. Chen, \& Ming H. Hsieh (Nov. 2007) The Dynamics of Implementing and Managing Modularity of Organizational Routines During Capability Development: Insights From a Process Model IEEE Transactions On Engineering Management, Vol. 54, No. 4

[47] Sumeet Kaur Sehra Yadwinder Singh Brar Navdeep Kaur (January 2012) Multi Criteria Decision Making Approach for Selecting Effort Estimation Model International Journal of Computer Applications (0975 8887) Volume 39- No.1

[48] Santosh Kumar Das, Abhishek Kumar, Bappaditya Das and A.P.Burnwal (2013) On Soft Computing Techniques In Various Areas Rupak Bhattacharyya et al. (Eds) : ACER 2013, pp. 59-68,CS \& IT-CSCP DOI : 10.5121/csit.2013.3206

[49] Selva Stauba , Emin Karamanb, Seyit Kayaa, Hatem KarapÕnara , Elçin Güvena ( 2015 ) Artificial Neural Network and Agility $1477-1485$ doi: 10.1016/j.sbspro.2015.06.448 World Conference on Technology, Innovation and Entrepreneurship

[50] Soumyadip Ghosh Aliza R. Heching, \& Mark S. Squillante,(2013) "A Two-Phase Approach For Stochastic Optimization Of Complex Business Processes" Proceedings of the 2013 Winter Simulation Conference

[51] S Xiaoji Liu, \& Yonghui Qin (2012) Successive Matrix Squaring Algorithm for Computing the Generalized Inverse A2 T Journal of Applied Mathematics, Article ID 262034, 12 pages doi:10.1155/2012/262034

[52] S.Sanyal, S.Iyeng (1993) Defuzzification Method For A Faster And More Accurate Control IEEE TENCON / Bcijn

[53] Saqib Ali, Ben Soh, \& Torabtorabi (August 2006) A Novel Approach Toward Integration Of Rules Into Business Processes Using An Agent-Oriented
Framework IEEE Transactions On Industrial Informatics, Vol. 2, No. 3

[54] Saeed Rouhani, Mehdi Ghazanfari, Mostafa Jafari (2012) Evaluation model of business intelligence for enterprise systems using fuzzy TOPSIS Expert Systems with Applications 39 3764-3771

[55] Tharwat O. S. Hanafy, H. Zaini, Kamel A. Shoush and Ayman A. Aly (January 2014) Recent Trends in Soft Computing Techniques for Solving Real Time Engineering Problems International Journal Of Control, Automation And Systems Vol.3 No.1 Issn 2165-8277 (Print) Issn 2165-8285

[56] Thoedtida Thipparat Prof. Elmer Dadios (Ed.) (2012) Application of Adaptive Neuro Fuzzy, Fuzzy Logic Algorithms, Techniques and Implementations, ISBN: 978-953-51-0393-6

[57] Thomas L. Saaty (2008) Decision making with the analytic hierarchy process Int. J. Services Sciences, Vol. 1, No. 1, 83 Copyright (C) 2008 Inderscience Enterprises Ltd

[58] Tzung-Pei Hong, Chai-Ying Leeb (1996) Induction of fuzzy rules and membership functions from training examples Fuzzy Sets and Systems 84 (1- 33 -47)

[59] Wil M.P. van der Aalst (Sep. 2004) "Workflow Mining: Discovering Process Models from Event Logs" IEEE Transactions on Knowledge and Data Engineering, Vol. 16

[60] Xiaohui Zhao \& Chengfei Liu (July 2010) Steering Dynamic Collaborations Between Business Processes IEEE Transactions On Systems, Man, And Cybernetics Part A: Systems And Humans, Vol. 40, No. 4

[61] Yi-Hong Tseng, Ching-Torng Lin (2011) Enhancing enterprise agility by deploying agile drivers, capabilities and providers Information Sciences 3693-3708

[62] Ying Bai and Dali Wang Fundamentals of Fuzzy Logic Control - Fuzzy Sets, Fuzzy Rules and De-fuzzifications

[63] Zixiong Peng, Xiaowei Chen Uncertain Systems are Universal Approximators

[64] Zohreh Hamedi, Shahram Jafari (2011) Using Fuzzy Decision-Making in E-tourism Industry: A Case Study of Shiraz city E-tourism IJCSI International Journal of Computer Science Issues, Vol. 8, Issue 3, No. 1, ISSN (Online): 1694-0814

[65] E. Czogala \& J. Leski, (2000) "Neuro-Fuzzy Intelligent Systems, Studies in Fuzziness and Soft Computing", Springer Verlag 


\section{APPENDIX}

\begin{tabular}{|c|c|c|c|c|c|}
\hline $\begin{array}{l}\text { Type of } \\
\text { Architecture ||| } \\
\text { Business } \\
\text { Process }\end{array}$ & Business & Information & Application & Data & $\begin{array}{l}\text { Technology } \\
\text { Infrastructure }\end{array}$ \\
\hline Management & $\begin{array}{l}\text { Vision, } \\
\text { Mission, Goal of the } \\
\text { HF for stakeholders }\end{array}$ & $\begin{array}{l}\text { XML Analysis } \\
\text { based on HIPPA } \\
\text { compliance }\end{array}$ & $\begin{array}{l}\text { Defining business } \\
\text { component based on } \\
\text { PAAS }\end{array}$ & $\begin{array}{l}\text { Enterprise Data Model for } \\
\text { user management and for } \\
\text { ontology services }\end{array}$ & \multirow{4}{*}{$\begin{array}{l}\text { Technology } \\
\text { parallel working } \\
\text { Docker } \\
\text { Qubernatives }\end{array}$} \\
\hline Core & $\begin{array}{l}\text { To understand G-XML } \\
\text { for medical note } \\
\text { To use NLP Engine to } \\
\text { generate ICT } 9 \text { code }\end{array}$ & $\begin{array}{l}\text { Preprocessing for } \\
\text { medical note, format } \\
\text { for input and output }\end{array}$ & $\begin{array}{l}\text { NLP engine as pool of } \\
\text { services, REST based } \\
\text { web services, KMS for } \\
\text { encryption key }\end{array}$ & $\begin{array}{l}\text { IDM GUID for user } \\
\text { management ER diagram } \\
\text { for IDM NLP Engine TBR } \\
\text { algorithm for generation of } \\
\text { key }\end{array}$ & \\
\hline Enabling & $\begin{array}{l}\text { Web services for } \\
\text { Throughput } \\
\text { based on TO BE } \\
\text { strategy, } \\
\begin{array}{l}\text { Authorization, } \\
\text { Authentication used } \\
\text { for user management }\end{array}\end{array}$ & $\begin{array}{lr}\text { User } & \text { GUID, } \\
\text { generation } & \text { of } \\
\text { encryption } & \text { key for } \\
\text { security, } & \end{array}$ & $\begin{array}{l}\text { OAuth process for } \\
\text { security Thread Pool } \\
\text { for NLP Engine }\end{array}$ & $\begin{array}{l}\text { Data Quality for GUID, } \\
\text { symmetric key }\end{array}$ & \\
\hline Enhancing & $\begin{array}{l}\text { Performance Analysis } \\
\text { model based on batch } \\
\text { processing }\end{array}$ & $\begin{array}{l}\text { SFTP account for } \\
\text { batch processing }\end{array}$ & $\begin{array}{l}\text { Queuing System based } \\
\text { on HDFS and Map } \\
\text { reduce }\end{array}$ & $\begin{array}{l}\text { Pingfederate for OAuth, } \\
\text { Medical notes are stored in } \\
\text { HDFS. MapReduce for } \\
\text { parallel requests to Reveal } \\
\text { server }\end{array}$ & \\
\hline
\end{tabular}

Table 2: HF System - As Per Architectural level and process type relationship proposed in the research paper 